This item was submitted to Loughborough's Research Repository by the author.

Items in Figshare are protected by copyright, with all rights reserved, unless otherwise indicated.

\title{
Design as a provocation to support discussion about euthanasia: The Plug
}

PLEASE CITE THE PUBLISHED VERSION

https://www.springer.com/us/book/9783319960647

\section{PUBLISHER}

Springer

\section{VERSION}

AM (Accepted Manuscript)

\section{PUBLISHER STATEMENT}

This is a pre-copyedited version of a contribution published in Bagnara, S. ... et al. (eds.) 20th International Ergonomics Association (IEA2018): Volume IX: Aging, Gender and Work, Anthropometry, Ergonomics for Children and Educational Environments published by Springer. The definitive authenticated version is available online via https://www.springer.com/us/book/9783319960647

\section{LICENCE}

CC BY-NC-ND 4.0

\section{REPOSITORY RECORD}

De Haas, M., Gyuchan Thomas Jun, and Sue Hignett. 2019. "Design as a Provocation to Support Discussion About Euthanasia: The Plug". figshare. https://hdl.handle.net/2134/32276. 
De Haas, M., Jun, G.T., Hignett, S. (2018) Design as a provocation to support discussion about euthanasia: The Plug Proceedings of the $20^{\text {th }}$ Triennial Conference of the International Ergonomics Association. Florence, Italy, 26-30 August.

\title{
Design as a Provocation to Support Discussion about Euthanasia: The Plug
}

\author{
Marije De Haas, G. Thomas Jun ${ }^{[0000-0002-0958-0107]}$, Sue Hignett ${ }^{[0000-0002-3025-7451]}$ \\ Loughborough University, Loughborough, UK
}

\begin{abstract}
Dementia affects 47 million people worldwide [1]. It is a collection or consequence of many illnesses with symptoms including deterioration in memory, thinking and behaviour; it is a terminal disease. The fear of dementia may lead people to signing an Advance Euthanasia Directive (AED). AEDs are rarely adhered to because the dementia symptoms conflict with the due care criteria; a person requesting euthanasia must be able to confirm the request at time of death and must be undergoing hopeless suffering. Once dementia has progressed, the euthanasia 'wish' can no longer be confirmed, and assessing suffering in a person with dementia is hard. This creates difficulties for physicians supporting patient wishes. Speculative Design is described as a way to prototype other realities [2]. This paper describes a Speculative Design to explore patient autonomy for end-of-life decisions in dementia. A video was developed to imagine the AED as an implant that would trigger a swift and painless death, once the conditions described in the AED were reached. Data were collected at the DementiaLab conference in Dortmund, Germany, September 2017. The workshop was attended by 15 participants of varying ages and backgrounds. The results found that the Speculative Design had potential to aid discussion between stakeholders, without each party needing to be a specialist. It sparked debate, but with a caveat about the importance of boundaries for awareness of the wider context and sensitivity to inherent bias.
\end{abstract}

Keywords: Dementia, Euthanasia, Speculative Design, Autonomy.

\section{Introduction}

Decision making for a good death in dementia is complex. This paper describes the use of Speculative Design for complex decision-making to explore why and how a person making an autonomous decision to opt for euthanasia can proceed (or not) with this decision when they have been diagnosed with dementia.

Dementia affects 47 million people worldwide with 9.9 million new cases each year [1]. Dementia is a collection or consequence of many illnesses, including Parkinson's disease, vascular dementia and Alzheimer's disease. There is a set of similar symptoms in which there is deterioration in memory, thinking and behaviour; it is a terminal disease. 
Euthanasia has many definitions from the Greek origins of 'good death' or 'easy death' [3] to the Nazi euphemism for the deliberate killings of physically, mentally, and emotionally handicapped people, leaving the term with extremely negative connotations [4]. The definition used in this paper is "The act of assisting someone who is terminally ill and whose suffering is unbearable and untreatable, to be in control of the manner of their dying." [2].

As euthanasia is illegal in most of the world, this paper will use the Dutch guidelines and legal framework [5], which states "euthanasia is not punishable if the attending physician acts in accordance with the statutory due care criteria. These criteria hold that: there should be a voluntary and well-considered request, the patient's suffering should be unbearable and hopeless, the patient should be informed about their situation, there are no reasonable alternatives, an independent physician should be consulted, and the method should be medically and technically appropriate" [6]. Euthanasia for people living with dementia is a complex issue because the symptoms clash with the due care criteria for euthanasia and unbearable suffering is difficult to assess in dementia [7-9]. It is hard for a person living with dementia to consent to euthanasia at the point of death because of the decline in their cognitive functioning [10]. In 2017 only three people with advanced dementia received euthanasia versus 166 cases of euthanasia in early stages of the disease, out of a total of 6,585 euthanasia cases in 2017 [11].

The dilemma between the need for consent and the challenges in obtaining it is addressed in this paper by offering a fictional solution (speculative design) as a framework for stimulating and supporting discussion.

\section{Literature Summary}

The systematic literature review used a seven-stage framework based on the PRISMA statement [12] for eligibility, search, identification of relevant papers from title and abstract, selection and retrieval of papers, appraisal and synthesis.

Seven databases were searched (Medline, Science Direct, Web of Science, PsychArticles, Cochrane Library, Scopus and PubMed) using the following search terms and criteria.

- String search: euthanasia OR “assisted suicide” OR "physician assisted suicide” AND dementia OR Alzheimer AND planning.

- Date range: 1994-2017. This range was selected as 1994 is when the Oregon Death with Dignity Act (ODDA) was passed, it specifies that a physician may prescribe lethal medication that is to be used to hasten death for competent, terminally ill persons who voluntarily request it [13].

- Language: Limited to Dutch and English as accessible literature and as the research is based on the Dutch legal framework.

- Geography: To include geographies where assisted dying is legal: Netherlands, Belgium and some US States.

As part of the inclusion/exclusion criteria the stance was taken that death is final so research literature about objections to euthanasia based on religious belief were not 
included. The literature was critically appraised using MMAT [14] and categorised into the following themes: Suffering, Autonomy and Planned Death.

This paper will only discuss the 'Autonomy' theme, which refers to control at the end-of-life whereby the only way to exercise control is by writing an Advance (Euthanasia) Directive.

\subsection{Autonomy}

"One of the most important ethical principles in medicine is respect for each patient's autonomy. When this principle conflicts with others, it should almost always take precedence." [15]

Being in control about ones' own end-of-life is a way to experience autonomy. Schroepfer, Noh, \& Kavanaugh [16] report that terminally ill people want to be in control over decision making, independence, mental attitude, instrumental activities of daily living and relationships. Creating an advance directive can give a person control over their end-of-life [17]. The option of assisted dying may also give a sense of control. Legalization of assisted dying may have a therapeutic benefit for terminally ill patients, who often report feeling more at peace merely by knowing that they have the option to end their lives when they want to [19-20].

However, if assisted dying is not an option, some people may choose to die by suicide. The effect of suicide on the people left behind can be much worse than a planned death. Families reported being better prepared for their loved ones death where people have requested assisted dying, and better able to accept it than those whose loved one has died 'naturally' of a terminal illness [21]. Not everyone wants to be in control of their own end-of-life decision; Cicirelli [22] studied end-of-life decisions for older people and found that approximately one third of participants $(n=388)$ favoured deferring end-of-life decisions to someone else, such as a family member, close friend, or physician. It has also been suggested that patient autonomy at the end of life does not exist as what is in the interests of the patient and what is in the interests of the surrounding family and friends will go hand-in-hand [23].

An advance directive is a tool used in planning for end-of-life. It is a document used to make provisions for health care decisions in the event that, in the future, the person becomes unable to make those decisions. Advance euthanasia directives in dementia are rarely complied with even though patient suffering may be judged to be extreme [11]. The way people adjust to suffering, a 'response shift', is sometimes argued to be the reason that dementia patients contradict earlier preferences, rendering advance directives meaningless. Jongsma et al [24] argue that a response shift is a change in self-evaluation of quality of life. As dementia patients lack the ability to self-evaluate, this results in complexities in measuring quality of life or even having an opinion on it. They conclude that advance directives cannot simply be ignored, though they also say that directives should not be blindly adhered to either.

Another major obstacle in advance planning and dementia is the personality change that is associated with dementia: "The core of the argument revolves around the undeniable change in personality, and arguably even identity, between the competent person who executed the directive and the incompetent person who will be affected by it" [25]. This can place a huge strain on physicians and health care prox- 
ies, who have to make life-and-death decisions on behalf of the person who wrote the advance directive. Essentially an advance directive is the formerly competent person asking his/her proxies to ignore their demented self. Several authors question if this is a fair question to ask loved ones $[7,9,26]$.

In practice advance directives are rarely adhered to in advanced dementia, which limits their role in advance care planning and end-of-life care of people with advanced dementia. Advance directives for euthanasia may raise false expectations and, in addition, place too much responsibility on elderly care physicians and relatives $[8,11,27,28]$. However, some literature did approach advance directives as a tool for adequate advance care planning in dementia. Burlá et al [18] suggested that the living will (advance directive) can be presented to the patient in the early days of their diagnosis and Flew [29] proposed a specific advance euthanasia directive that should be adhered to, even in advanced dementia. Others are aware of the problems with advance directives in dementia and propose solutions. For example, Gastmans \& de Lepeleire [30] claim that, in an ethical evaluation of euthanasia, the dignity of the human person, relational autonomy, quality of life and care must be observed. They introduced the concept of 'relational autonomy' to give more control to close fami$\mathrm{ly} /$ friends and social context of the person with dementia.

Menzel and Steinbock [31] describe identity in reference to Dworkins' 'critical interests'; these can be described as life values and go beyond 'experiential interests' which only exist in the here and the now. The critical interests shape a person and describe the kind of person they are and want to be - these are the interests that should be protected in an advance directive. This causes a dilemma: if the experiential interests of the person with dementia are not violated once dementia takes hold, but conflict with their critical interests. The authors propose a sliding scale solution, where autonomy is weighed against capacity of enjoyment, on a case by case assessment. Advance directives give people control over their lives once they themselves are no longer capable; "the way they die is an important reflection on the way they lived" and should be taken into consideration [31].

\subsection{Interpretation of the Literature: Outlining the Problem Space}

It is important that patients and their carers understand that their advance directives will not easily apply in dementia. There may be false hope attached to these directives, that may be reassuring to the person diagnosed with dementia while they are still cognitively sound, but likely to be a source of much distress to their proxies once the disease has progressed, and this document is largely ignored. A conflict arises between a person's 'critical interests' and 'experiential interests'. It can be said that people living with dementia, certainly in the later stages of the disease, live in the moment. Their personhood, based on their critical interests, their life values, ceases to exist to the person living with dementia, but not to their proxies.

The case in favour of adhering to an advance euthanasia directive based on a person's autonomy, does not take into account the implementation of the directive. Is it ethical to ask carers and clinicians to act upon an advance directive when the facts, in that time, do not endorse the earlier directive? The responsibility to adhere to a eutha- 
nasia request lies with a general practitioner (GP). In the Netherlands, a person usually has the same GP over a long period of time (near place of residence). The GP should know the person well, and will have discussed the advance directive. Additionally, a second specialist physician will be involved to carefully assess the request. However, this raises the question whether euthanasia decisions should be made by physicians alone, as there are more dimensions beyond a physical death that could require other specialist capacities [32,33].

The key points from the literature review are:

- People should be able to make an autonomous decision about their end-oflife; they can exert control by making an advance (euthanasia) directive.

- Advance euthanasia directive are not adhered to in dementia, because the disease presents with personality change and the disease makes suffering impossible to assess.

- $\quad$ The parties having to execute the wish expressed in an advance directive are faced with a difficult moral decision; do they respect the person who has written the directive, or the 'new' person the directive is about?

\section{Speculative Design as a Method to Explore this Debate}

The term Speculative Design was coined by Dunne \& Raby [34] as design used to stimulate discussion and debate amongst designers, industry and the public about the social, cultural and ethical implications of existing and emerging technologies. Design Fiction is described by Bleecker [2] as a thoughtful exploration of speculative scenarios; a way to prototype other realities; this practise has also been called Speculative Design, Critical Design, Design Probes and Discursive Design. All these design research practices are similar in that that there are no commercial constraints, all use fiction to present a diegetic alternative to existing issues, and prototypes as a method of enquiry [35]; for this research the term Speculative Design will be used. Ways of collecting data from Speculative Designs vary greatly. Speculative Designs are often placed in an exhibition context and left for public debate [35], or used as a tool to aid discussion [36,37]. Tanenbaum [38] positions design fiction as storytelling "Situating a new technology within a narrative forces us to grapple with questions of ethics, values, social perspectives, causality, politics, psychology, and emotions”. These stories are important, as the prototypes created exist only within these stories, and this is precisely what makes them fictional [39]. For this research, Speculative Design is approached as a practical thought experiment. A thought experiment considers a hypothesis for the purpose of thinking through consequences and thought experiments are frequently used in philosophy and physics. The thought experiment can make the offered choice more real to result in a different kind of discussion [40].

There is no specific method on how to construct a successful speculation, but there are a few guidelines: A design speculation is a concept about a possible future. This speculation can be critical about a likely future, or it can be more like a 'what if' scenario for a desirable future [34,41]. It is suggested that a speculation should sit inbetween normal life and fiction. The story should be probable and credible, the viewer 
should be able to "suspend their disbelief" about the proposed prototype [42]. Auger [35] proposes that the speculation should offer a bridge between reality and the fictional element of the concept; in order to get the audience engaged, provocations can be used but they must be dealt with carefully, especially for controversial subjects (such as death), as the provocation can lead to revulsion or shock. He calls this "managing the uncanny", shifting focus between familiarity and the proposed idea are ways to manage the experience of the uncanny. In this research, within the context of euthanasia and dementia, design is used as an anchor point between the different stakeholders; people with dementia, non-professional care-givers and professional care-givers.

\section{Design Decisions: How the Speculation was Constructed}

This section will explain how the Speculative Design was constructed to illustrate the problem space. The designed prototypes aimed to make the euthanasia in dementia debate more tangible and accessible.

\section{Speculative Design: The AED-Plug}

This Speculative Design is called the Advance Euthanasia Directive Plug (Figure 1; https://vimeo.com/231854700; http://aed-plug.com/). The proposed design is an implant that, once the conditions are reached as described in the Advance Euthanasia Directive, would trigger a swift and painless death.

This speculation was developed from the literature on Advance Euthanasia Directives for dementia. As discussed earlier, some authors argue that if an autonomous person has made an Advance Euthanasia Directive, then this should be adhered to. This adherence at all cost to an Advance Euthanasia Directive can put a lot of strain on clinicians having to enact this order. The Speculative Design explores an idea to remove this strain with a new kind of advance euthanasia directive, the "AED-Plug", implanted in a fully cognitively competent person. Should this person develop dementia, they can be sure their euthanasia wish would be complied with, without upsetting clinicians, or putting stress on their proxies.

A Design Speculation requires a connection to exist between the audience perception of their world and the fictional element of the concept [35]. In order to make the speculation credible, and be taken seriously, the audience member must be able to believe in the possibility of its existence. This prototype was crafted in such a way that it could already be in existence, using contemporary media and messages (Fig.1). It was presented as an advertorial; walking a fine line between documentary and commerce.

\section{The Video (Design Speculation)}

Introduction

A black background and a 'neutral' typeface was used (Akzidenz Grotesk). The black background was chosen to communicate death, with a large size type, as the message is generally aimed at an older generation [43]. 

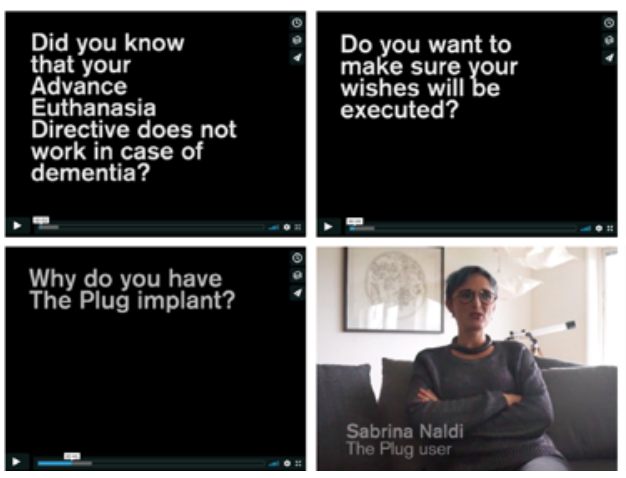
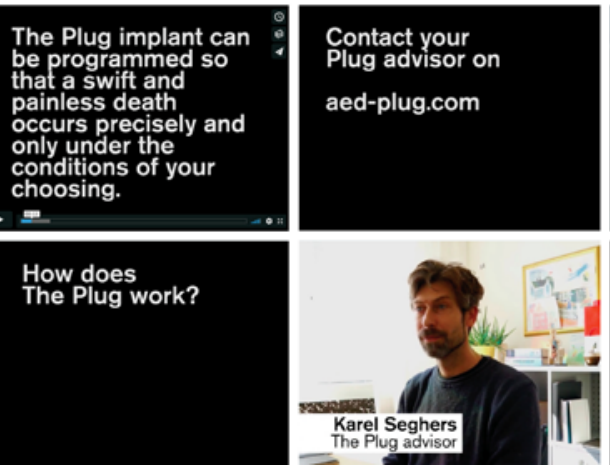

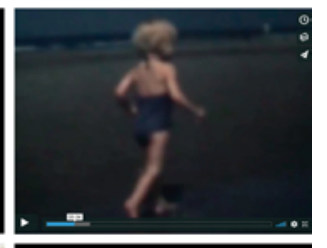

Fig. 1. Screenshots from the video about The Plug

Music

The soundtrack used was entitled “Death with Dignity”, by Sufjan Stevens. The music is melancholy yet positive, filled with hope. The reveal of the title in the end credits is important as the title of the track is relevant to the topic.

\section{Super 8 footage}

The super 8 footage is introduced, an intentional break in the message, and to conceptually visualise a sense of (memories) lost.

\section{Actor 1 (Sabrina Naldi)}

- Casting: An Italian woman in European setting, well-educated and well-travelled.

- Setting: Set in Sabrina's home, artworks on the wall, a telescope in the background, to indicate that Sabrina is a woman of the world.

- Monologue: Sabrina is passionate and well informed. She has clearly given the subject matter serious thought and made a rational decision. Some distance is created by the language used, demonstrating that she clearly knows what she is talking about. Her eloquence is convincing with the intention that the viewer can identify with her.

- Filming: The camera was positioned at an angle and Sabrina is engaged in conversation with the interviewer. Filmed as a single shot the intention was that complete story behind Sabrina's rationale is revealed to the viewer.

\section{Actor 2 (Karel Seghers)}

- Casting: Karel is a Dutch physician who has taken on a new role as AEDPlug advisor. Karel is pragmatic, working within the framework of the Dutch legal system, doing what he believes is the right thing.

- $\quad$ Setting: Karel's office, but not too formal, Karel is wearing informal clothes and his office hints of a family life with children's drawings on the wall.

- Dialogue: Karel explains in lay terms how the plug works, referencing familiar medical implants (pacemaker), to create familiarity. 
- Filming: The camera is positioned at an angle and Karel is engaged in conversation with the interviewer. The film was cut at several points to give the idea that perhaps the way the Plug works is a little more complicated than this edit shows.

Credits

The credits reveal that this is a fictional scenario.

\section{$5 \quad$ Review of the Speculative Design}

The Speculative Design video was used to aid discussion in a workshop at the DementiaLab conference in Dortmund, Germany, September 2017. The workshop was attended by 15 participants of varying ages and backgrounds. All were active within dementia as designers, professional care-givers and/or academics. This workshop was run as a pilot study, to test the validity of the concept and to inform how data collection could best be done on this speculation with a group of carefully selected participants. Future participant criteria are that the participants need to be Dutch (or living in the Netherlands): a cultural acceptance of euthanasia as a common practise, who have either personal of professional experience with Dementia. Results of this research will be discussed during the conference. Ethical approval was given from Loughborough University.

\subsection{Workshop Structure and Questions}

The workshop was structured into three sections with the speculation carefully introduced to avoid the "uncanny" [35]. The first section was an introduction to dementia and dying. It featured subjective images from a caregiver's perspective on the disease (Fig. 2), expressing that this disease can be tough. A summary of the literature about euthanasia and dementia was given, focussing on autonomy and advance euthanasia directives.

The second part of the workshop was designed to help the participants become more comfortable talking about death and dying and featured three activities. The first activity was drawn from a podcast on "how to die a good death" [44]. Participants were asked to choose their preferred demise from the four most common ways to die in western society; heart disease, stroke, dementia and (lung) cancer [45]. This was followed with an exercise discussing celebrity deaths (including Princess Diana, Robin Williams) where the participants were asked rate the quality of four different deaths; an accident, a suicide, cancer and old age. Finally, in this section, the participants were asked to create their ideal death scene in Lego. 


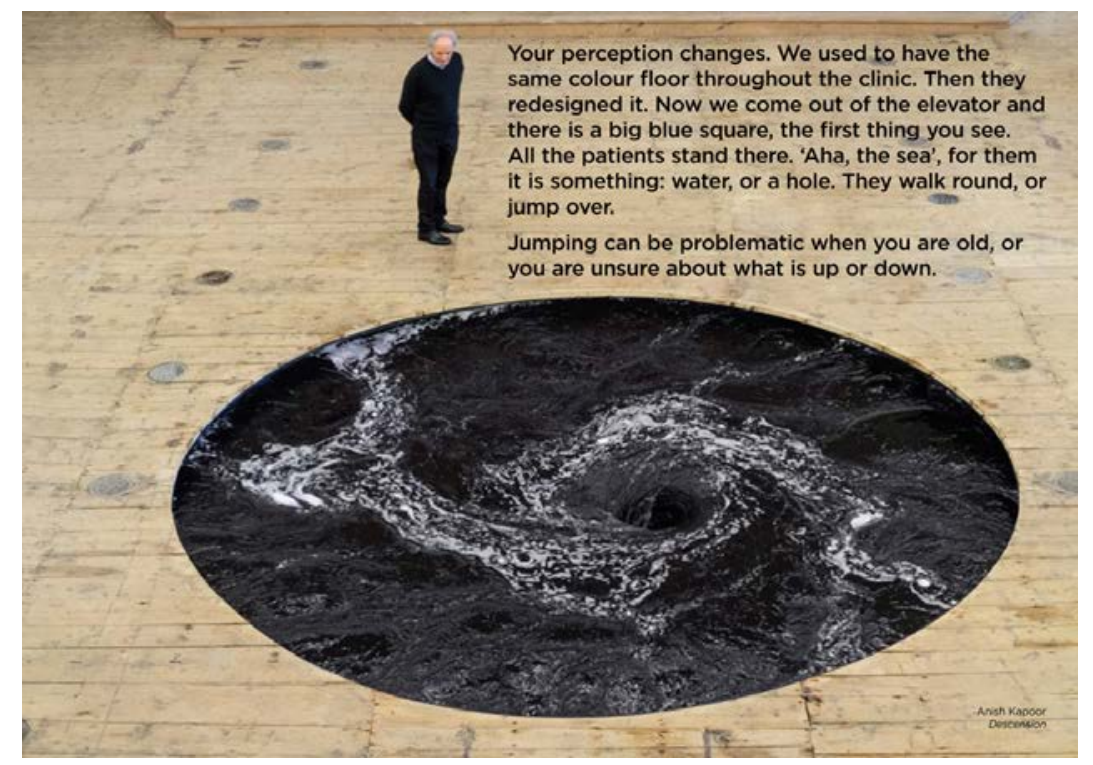

Fig. 2. Subjective image with quotes from Per Lundgren, Dementia nurse for over 37 years (interviewed by author on 18.02.16). Image: https://www.designboom.com/art/anish-kapoordescension-public-art-fund-brooklyn-bridge-park-new-york-02-17-2017/

The third part of the workshop introduced the Speculative Design video (section 4). After watching video, the participants were asked to discuss three questions:

1. What factors, other than patient autonomy, should be considered for end-oflife decisions in dementia?

2. Who should be involved in making these end-of-life decisions?

3. Is Speculative Design a useful tool to further this debate?

Data were collected to critically appraise the Design Speculation and consider methods to further the speculation within the wider context of the euthanasia in dementia debate.

\subsection{Workshop Results}

The responses to the three questions are outlined below.

What factors, other than patient autonomy, should be considered for end-of-life decisions in dementia?

Opinions differed greatly for this question and a lot of concerns were raised. For example

- Was dementia really that bad?

- Why would people want to take their own lives?

- Was it not our responsibility to make sure people wouldn’t want to die?

Some participants felt dementia wouldn't be that bad, whereas others found it more problematic and felt strongly that there should be a choice: "Living with dementia 
doesn't have to be negative - but I, for myself, would like to have a choice. And I, now at this point, don't want to be that person [with dementia], no matter how happy I am going to be at that point, because that is not me. I felt very strongly with this woman in the video, who talked about these two personalities, for me it felt very relatable."

The change in personality was addressed with arguments that personality change could be part of personal growth, and that a person could not make a decision now about their future self. It was concluded that The Plug would have to be an option, not an obligation. The decision would have to lie with the person diagnosed with dementia, meaning patient autonomy should be the main consideration.

\section{Who should be involved in making these end-of-life decisions?}

Discussions included extended life, questioning decisions to keep people with dementia alive “... in hospital people try to keep them alive as much as possible like, you know, feeding them through tubes, that's so invasive, is it really needed? It is also horrible thinking, will she die from starving? I mean, and is ... I don't know if ... for instance ... in those moments, the relatives could have some kind of say."

Another participant introduced the concept of an Artificial Intelligence to make the decision for you leading to interesting thoughts: "You could hack the Plug... Kill them... Or keep them alive!"

An important issue was raised about changing the decision "the problem with the human heart and the human mind is that it's not constant and we change our minds and I'm afraid that I might change my mind and someone is not going to [help me]".

\section{How useful is Design Fiction as a tool to further this debate?}

The offered speculation triggered debate but and raised new questions. The speculation was successful in the way it clearly communicated the complicated issues extracted from the literature, and helped to move away from the original dilemma: 'the need for consent the difficulty obtaining this consent', to new questions such as 'the ethical implications of giving authority to an artificial devise' to 'how to deal with a response shift' to 'a right to die'. A lot of positive feedback was received about the workshop with the design speculation making people think differently about end-oflife. Some people felt confronted and some even angry, but all were happy to be challenged. Additional questions and comments were received after the workshop as the subject matter was further considered including a question about economics, and the impact that the cost of caring for dementia could have on decisions " $a$ strange power conflict". The designed speculation was successful in improving the accessibility (and discussion) for the complexities surrounding euthanasia in dementia. The workshop participants grasped complicated ethical dilemmas after watching a short video. It must be noted that the speculation, and the results it obtained will inherently be biased. 


\section{Developing the Design Speculation: From 'What If?' to 'Then What?'}

To give the Design Speculation more depth, the next stage was to follow the 'what if' of the proposed implant (The Plug), to the 'then what?' A website was designed using more of the discussion points from the workshop. In the workshop people wondered what it would look like, how would it actually work and what would happen in case of (technical) failure. A website was developed to give the impression that The Plug was commercially available (http://aed-plug.com/) with a contemporary style, lay terminology for accessibility and common menu items. The website sections include:

\section{What is The Plug?}

This section on the website refers to research literature to give an evidence base.

\section{How does it work?}

The Plug is a small implant that functions 'like a reverse pace-maker'. Here we show what the implant looks like, and shows a personalised box on how one would receive this Plug (Fig. 3). A simple illustration (Fig. 4) explains how The Plug would work with information received from sensors and medical data. This section is expanded to show how the information gathered from the sensors can make decisions based on a Boolean string type of query (Fig. 5).
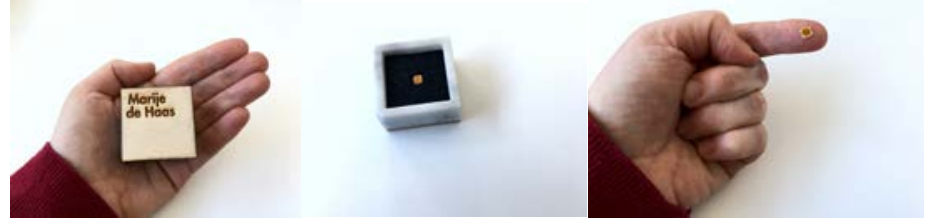

Fig. 3. What does the AED-Plug look like?

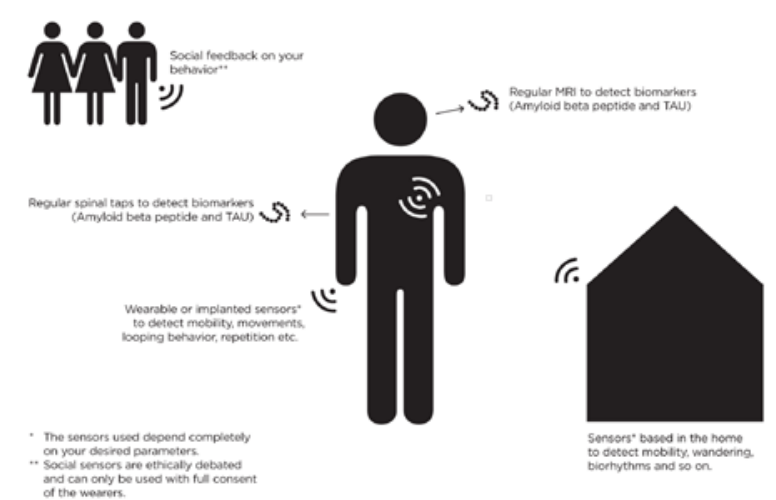

Fig. 4. How does the Plug know? 
EXAMPLE: CONDITIONS FOR DEATH

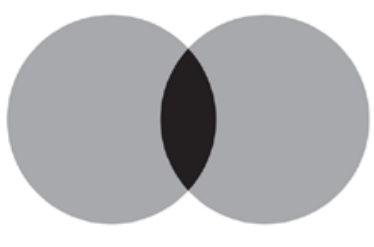

Can't groom myself Don't want to eat

AND

If I can't groom myself

(shower, tollet, get dressed).

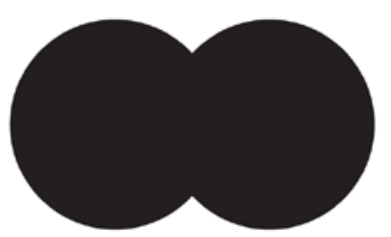

Don't remember my wife Don't remember my child

OR

If I can't remember my wife

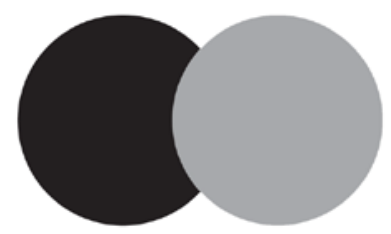

Don't remember my child Going to the toillet unassisted NOT

If I can't remember my child, but I don't really care if I ne

Fig. 5. Decision-making process for the Plug.

\section{Frequently Asked Questions}

These answer questions raised in the workshop, such as "can I change my mind?”, "will there be pain?” and “what if it doesn't work?”

\section{The Plug in the News}

Two very different media stories were created for inclusion on the website to show how The Plug could go wrong (Fig. 6), or could be perceived to go wrong (Fig. 7).

The first story (Fig. 6) is shown as a fictional design hosted by the BBC to add credibility. It reports a case of The Plug not working to illustrate the complexity for specific conditions that may not be met by sensor-based technologies.

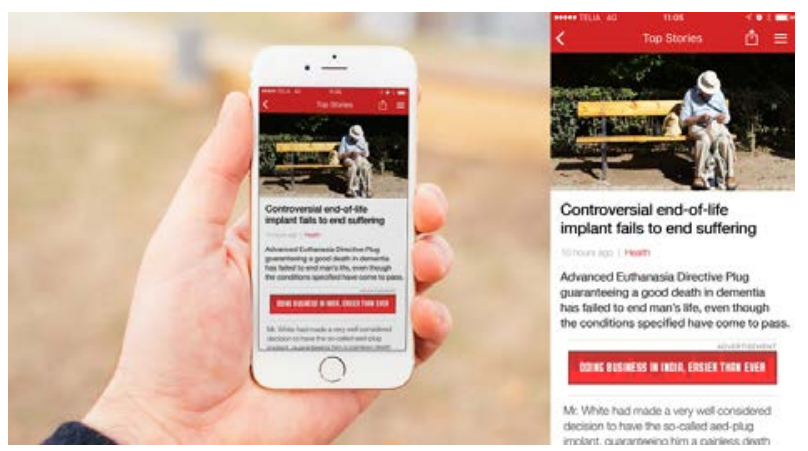

Fig. 6. Story 1: 'Controversial end-of-life implant fails to end suffering'

The second story (Fig. 7) is also designed as a fictional story reported in The Sun (UK tabloid newspaper). It suggests a more aggressive Plug design with the potential to kill innocent people.

The full design speculation (video and website) will encourage discussion between participants including people living with dementia, non-professional and professional care-givers. 


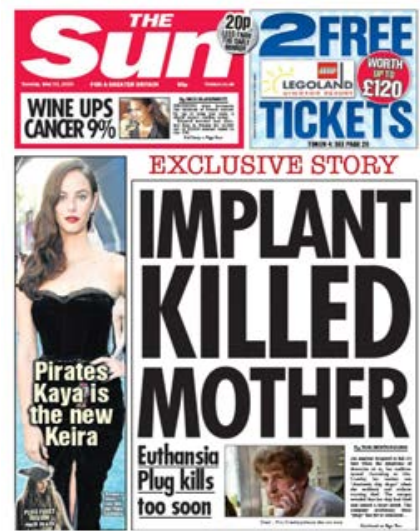

Fig. 7. Story 2: 'Implant killed mother’

\section{Discussion}

In creating a Design Speculation to explore the autonomy theme in the euthanasia for dementia debate, there is a need to acknowledge bias. The focus was to explore the dilemma between making an Advance Euthanasia Directive and then assuming it will be enacted with two contrasting perspectives:

- An Advance Euthanasia Directive is sufficient safeguarding for future endof-life decisions in dementia.

- An Advance Euthanasia Directive cannot be adhered to in dementia, because the disease presents with personality change and additionally it makes suffering impossible to measure.

This research has attempted to explore the challenges faced in the moral dilemma for the physician having to enact the directive. The Design Speculation has attempted to move the responsibility of that final decision from the physician to the person with dementia. The danger with presenting this Design Speculation in the wider context of euthanasia in dementia is that it presents inherent bias by enabling the possibility of euthanasia in dementia, therefore the framing is important to clarify that the purpose is to explore autonomy.

As a critique of the method (Speculative Design) one issue is the credibility (and quality) of the Design Speculation, so the way that it is crafted may have an impact on how it is perceived. To address this potential bias, it is important to document and reflect on the purpose of speculation. Few guidelines exist on how to create a good Speculative Design and it is important to "suspend disbelief" [42] - Auger [35] has suggested guidelines on how to achieve this. However, further research is needed to develop ways to critically access the quality of design speculations. This is a challenge as there may be little or no comparative material within the same context so a critical review of literature on the crafting of design fictions may offer some ideas and insights $[35,36,46]$. This paper has tried to describe how the speculation was designed and why the specific design decisions were made, as a knowledge contribution to 
future guidelines/education on crafting evidence-based design speculations. However, as with any design, quality can only really be judged in relation to the context and purpose (usability, functionality) of the design created.

\section{Conclusion}

The euthanasia in dementia debate is at an impasse. The intention for producing a Speculative Design was to offer a new perspective on this dilemma by designing a platform for reframing questions. Further testing is required to explore the value of this speculative design in reframing these questions, especially with the key stakeholders: people living with dementia, non-professional and professional care-givers.

However, this research has shown that there are benefits in presenting a dilemma, such as euthanasia in dementia, in a different format. The Speculative Design has potential to aid discussion between various stakeholders, without each party needing to be a specialist. The use of a provocative speculation was found to spark debate, but a caveat is the importance of boundaries whereby stakeholders are made aware of the greater context of the problem space so that inherent bias is addressed.

\section{References}

1. WHO, http://www.who.int/mediacentre/factsheets/fs362/en/, 2017

2. Bleecker, J. (2009). Design Fiction: A Short Essay on Design, Science, Fact and Fiction. Near Future Laboratory, (March), 49.

3. dictionary.com, 2017

4. Euthanasia, Wikipedia (2017), https://en.wikipedia.org/wiki/Euthanasia

5. Learner's dictionary, http://learnersdictionary.com/definition/euthanasia, 2018

6. Dutch Euthanasia Act, 2002. https://www.rijksoverheid.nl/onderwerpen/levenseinde-en-euthanasie/euthanasie

7. Buiting, H. M., Gevers, J. K. M., Rietjens, J. a C., Onwuteaka-Philipsen, B. D., van der Maas, P. J., van der Heide, A., \& van Delden, J. J. M. (2008). Dutch criteria of due care for physician-assisted dying in medical practice: a physician perspective. Journal of Medical Ethics, 34(9), e12. http://doi.org/10.1136/jme.2008.024976

8. Hertogh, C. M. P. M. (2009). The role of advance euthanasia directives as an aid to communication and shared decision-making in dementia. Journal of Medical Ethics, 35(2), 100-3. http://doi.org/10.1136/jme.2007.024109

9. Rietjens, J. A. C., van Tol, D. G., Schermer, M., \& van der Heide, A. (2009). Judgement of suffering in the case of a euthanasia request in The Netherlands. Journal of Medical Ethics, 35(8), 502-507 6p. http://doi.org/10.1136/jme.2008.028779

10. Emanuel, E. J. (1999). What is the great benefit of legalizing euthanasia or physician-assisted suicide? Ethics 109, no.3 (629-642). https://doi.org/10.1086/233925 
11. Rurup, M. L., Onwuteaka-Philipsen, B. D., Van Der Heide, A., Van Der Wal, G., \& Van Der Maas, P. J. (2005). Physicians' experiences with demented patients with advance euthanasia directives in the Netherlands. Journal of the American Geriatrics Society, 53(7), 1138-1144. http://doi.org/10.1111/j.15325415.2005.53354.x

12. NRC Handelsblad, https://www.nrc.nl/nieuws/2018/03/08/het-om-wil-nu-zelfgrenzen-euthanasie-onderzoeken-a1594903, 2018

13. www.prisma-statement.org, 2018

14. Fenn, D. S., \& Ganzini, L. (1999). Attitudes of Oregon psychologists toward physician-assisted suicide and the Oregon Death With Dignity Act. Professional Psychology, Research and Practice, 30(3), 235-44. http://doi.org/10.1037/07357028.30.3.235

15. MMAT,

http://mixedmethodsappraisaltoolpublic.pbworks.com/w/file/fetch/84371689/M MAT\%202011\%20criteria\%20and\%20tutorial\%202011-06-

29updated2014.08.21.pdf, 2018

16. Billings, J. A. (2011). Double effect: a useful rule that alone cannot justify hastening death. Journal of Medical Ethics, 37(7), 437-40. http://doi.org/10.1136/jme.2010.041160

17. Schroepfer, T. A., Noh, H., \& Kavanaugh, M. (2009). The myriad strategies for seeking control in the dying process. Gerontologist, 49(6), 755-766. http://doi.org/10.1093/geront/gnp060

18. Burlá, C., Rego, G., \& Nunes, R. (2014). Alzheimer, dementia and the living will: A proposal. Medicine, Health Care and Philosophy, 17(3), 389-395. http://doi.org/10.1007/s11019-014-9559-8

19. Rosenfeld, B. (2000). Assisted suicide, depression, and the right to die. Psychology, Public Policy, and Law, 6(2), 467-488. http://doi.org/10.1037//1076-8971.6.2.467

20. Brock, D. W. (2000). Misconceived sources of opposition to physician-assisted suicide. Psychology, Public Policy, and Law: An Official Law Review of the University of Arizona College of Law and the University of Miami School of Law, 6(2), 305-313. http://doi.org/10.1037/1076-8971.6.2.305

21. Carlson, W. L., \& Ong, T. D. (2014). Suicide in Later Life. Failed Treatment or Rational Choice? Clinics in Geriatric Medicine, 30(3). http://doi.org/10.1016/j.cger.2014.04.009

22. Cicirelli, V. G. (1997). Relationship of psychosocial and background variables to older adults' end-of-life decisions. Psychology and Aging, 12(1), 72-83. http://doi.org/10.1037/0882-7974.12.1.72

23. Hardwig, J. (1997). Is there a duty to die? Hastings Center Report, 27(2), 34-42.

24. Jongsma, K. R., Sprangers, M. A. G., \& van de Vathorst, S. (2016). The implausibility of response shifts in dementia patients. Journal of Medical Ethics, medethics-2015-102889. http://doi.org/10.1136/medethics-2015-102889

25. Davis, D. S. (2014). Alzheimer disease and pre-emptive suicide. Journal of Medical Ethics, 40(8), 543-549. http://doi.org/10.1136/medethics-2012-101022

26. Bernheim, J. L., Distelmans, W., Mullie, A., \& Ashby, M. A. (2014). Questions and Answers on the Belgian Model of Integral End-of-Life Care: Experiment? 
Prototype? Journal of Bioethical Inquiry, 11(4), 507-529. http://doi.org/10.1007/s11673-014-9554-z

27. De Boer, M. E., Dröes, R. M., Jonker, C., Eefsting, J. A., \& Hertogh, C. M. P. M. (2011). Advance directives for euthanasia in dementia: How do they affect resident care in dutch nursing homes? Experiences of physicians and relatives. Journal of the American Geriatrics Society, 59(6), 989-996. http://doi.org/10.1111/j.1532-5415.2011.03414.x

28. Kouwenhoven, P. S. C., Raijmakers, N. J. H., van Delden, J. J. M., Rietjens, J. A. C., van Tol, D. G., van de Vathorst, S., van Thiel, G. J. M. W. (2015). Opinions about euthanasia and advanced dementia: a qualitative study among Dutch physicians and members of the general public. BMC Medical Ethics, 16(1), 1-6 6p. http://doi.org/10.1186/1472-6939-16-7

29. Flew, A. (1999). Advance directives are the solution to Dr Campbell's problem for voluntary euthanasia. Journal of Medical Ethics, 25(3), 245-6.

30. Gastmans, C., \& De Lepeleire, J. (2010). Living to the bitter end? A personalist approach to euthanasia in persons with severe dementia. Bioethics, 24(2), 78-86. http://doi.org/10.1111/j.1467-8519.2008.00708.x

31. Menzel, P., \& Steinbock, B. (2013). Advance Directives, Dementia, and Physician-Assisted Death The Journal of Law, Medicine \& Ethics Vol 41, Issue 2, pp. 484 - 500, https://doi.org/10.1111/jlme.12057

32. Bosshard, G., Broeckaert, B., Clark, D., Materstvedt, L. J., Gordijn, B., \& Müller-Busch, H. C. (2008). A role for doctors in assisted dying? An analysis of legal regulations and medical professional positions in six European countries. Journal of Medical Ethics, 34(1), 28-32. http://doi.org/10.1136/jme.2006.018911

33. Daly, P. (2015). Palliative sedation, foregoing life-sustaining treatment, and aidin-dying: what is the difference? Theoretical Medicine and Bioethics, 36(3), 197-213. http://doi.org/10.1007/s11017-015-9329-5

34. Dunne \& Raby (2013), Speculative everything: Design, Fiction, and Social Dreaming. MIT Press, ISBN:0262019841 9780262019842

35. Auger, J. (2013). Speculative design: crafting the speculation. Digital Creativity, 24(1), 11-35. http://doi.org/10.1080/14626268.2013.767276

36. Tsekleves, E., Darby, A., Whicher, A., \& Swiatek, P. (2017). Co-designing Design Fictions : a New Approach for Debating and Priming Future Healthcare Technologies and Services, 5-21.

37. Malpass, M. (2017). Critical Design in Context, History, Theory, and Practices. Bloomsbury, ISBN 978-1-4725-7518-0

38. Tanenbaum, J. (2014). Design Fictional Interactions: Why HCI should care about stories, 22-23. http://doi.org/10.1145/2648414

39. Lindley, J., \& Coulton, P. (2016). Pushing the Limits of Design Fiction: The Case For Fictional Research Papers.

40. Stanford Encyclopedia of Philosophy, 2014, https://plato.stanford.edu/entries/thought-experiment/

41. Blythe, M. (2014). Research Through Design Fiction: Narrative in Real and Imaginary Abstracts.

42. Sterling, B. (2009). Design Fiction. Interactions, 16(3), 20. http://doi.org/10.1145/1516016.1516021

43. Fonts.com (2017), https://www.fonts.com/content/learning/fyti/situational- 
typography/designing-for-seniors

44. The Guardian Podcast (2016), Utopia 2016: How to die a good death, https://www.theguardian.com/membership/audio/2016/nov/01/utopia-2016how-to-die-a-good-death-guardian-live-event-podcast. Minutes 15:17-16:27

45. WHO, The top ten causes of death (2017), http://www.who.int/mediacentre/factsheets/fs310/en/index1.html

46. Schulte, B. F., Marshall, P., \& Cox, A. L. (2016). Homes For Life: A Design Fiction Probe. Proceedings of the 9th Nordic Conference on Human-Computer Interaction, 80:1--80:10. http://doi.org/10.1145/2971485.2993925 